\title{
Targeting Cancer Cell Metabolism with Metformin, Dichloroacetate and Memantine in Glioblastoma (GBM)
}

\author{
Gulsah ALBAYRAK ${ }^{1}$, Ece KONAC ${ }^{1}$, Umit Akin DERE², Hakan EMMEZ² \\ ${ }^{1}$ Gazi University, Faculty of Medicine, Department of Medical Biology and Genetics, Ankara, Turkey \\ ${ }^{2}$ Gazi University, Faculty of Medicine, Department of Neurosurgery, Ankara, Turkey \\ Corresponding author: Ece KONAC ecemercanoglu@yahoo.com
}

\section{ABSTRACT}

AIM: To investigate the effects of metformin, dichloroacetate (DCA), and memantine on T98G and U87-MG human glioblastoma (GBM) cells to target tumor cell metabolism in a multi-directional manner.

MATERIAL and METHODS: IC50 levels for metformin, DCA, metformin+DCA and memantine were determined by MTT assay in T98G and U87-MG cells in vitro. Casp3, Bcl-2, Bax, c-Myc and GSK-3B protein expressions were investigated post treatments. Fifteen GBM+ tumor tissues were assessed for Casp-3, Bcl-2, Bad, Bax for apoptotic protein expression patterns.

RESULTS: Cancer cell metabolism targeting drugs metformin, DCA, metformin+DCA and memantine induced cytotoxicity in a dose-dependent manner in T98G and U87-MG cells. IC50 for memantine is found as $0.5 \mathrm{mM}(\mathrm{p}<0.01)$ which is nearly 10 times lower concentration than that of metformin. Fifteen GBM+ tumor tissues had differential apoptotic protein expressions.

CONCLUSION: Memantine exerted anti-cancer mechanism of action in T98G and U87-MG cells, however, such a mechanism requires deeper investigation for GBM treatment.

KEYWORDS: Glioblastoma, Cancer cell, Metabolism, Metformin, Dichloroacetate, Memantine

\section{INTRODUCTION}

$\mathrm{G}$ lioblastoma (GBM) is one of the most aggressive tumors of the central nervous system, and represents approximately $50 \%$ of all glial tumor types $(12,27)$. The median survival rate for GBM patients does not change significantly using the current standard of care treatments, which involve tumor resection followed by radiotherapy and Temozolomide treatment. The median survival is approximately 12-14 months despite the combined use of surgery, radiotherapy and chemotherapy $(7,23)$.

GBM tumors have a wide range of genetic variations leading to different therapeutic responses $(5,9,21)$. Intratumor heterogeneity might be the key to identify the cause of treatment failure (22). Chemotherapy drugs such as Temozolamide increases the mutational load within the cancer genome when compared to the untreated GBM cells (17). Alternative therapy approaches, therefore, are urgently needed in GBM treatment.
Metformin is a common anti-diabetic drug used in Type 2 diabetes treatment (18). Metformin treatment is found to be associated with a lower risk of several cancers, however, its effects on GBM has not been well characterized $(4,24)$. Metformin treatment decreases Temozolomide resistance in GBM cells (26). Metformin, however, has safety concerns in clinical setting as most of the preclinical works used supraphysiological doses of metformin (25). In this study we aimed to overcome this challenge by investigating the effect of metformin by combining it with dichloroacetate (DCA) that targets cancer cell metabolism via pyruvate dehydrogenase kinase inhibition (11). Targeting cancer cell metabolism might have implications for the treatment of aggressive GBM. Furthermore, we aimed to investigate the apoptotic protein expression profiles to better understand GBM at a molecular level. We also aimed to interfere cancer cell metabolism using metformin, DCA and memantine in T98G and U87-MG GBM cell lines.
Gulsah ALBAYRAK (1) : 0000-0001-9106-5798 Ece KONAC (1) : 0000-0001-5129-2515
Umit Akin DERE (1) : 0000-0002-6678-6224

Hakan EMMEZ (1) : 0000-0002-3290-179X 


\section{- MATERIAL and METHODS}

\section{Cell Culture and Chemicals}

T98G and U87-MG human glioblastoma cell lines were provided from ATCC. T98G and U87-MG cells were grown in DMEM/F12 medium supplemented with 10\% Fetal bovine serum (FBS) (Sigma-Aldrich, St Louis, MO, USA). Cells were grown in a $5 \% \mathrm{CO}_{2}$ incubator at $37^{\circ} \mathrm{C}$. Metformin, dichloroacetate and memantine were provided from SigmaAldrich, St Louis, MO, USA. Cells were treated with these agents for $48 \mathrm{~h}$. to determine IC50 levels. All agents were dissolved in sterile distilled water.

\section{Cell Cytotoxicity Assay}

$3 \times 10^{3}$ T98G and U87-MG cells were seeded into a 96-well plate and cultured overnight. Different concentrations of metformin, DCA and memantine were used in MTT assay. MTT solution (5 mg/ml in PBS) was added and cells were further incubated for 4 hours at $37^{\circ} \mathrm{C}$. DMSO was added to solubilize crystals. Absorbance ratio was measured using SpectraMax M3 (Molecular Devices, USA)

\section{GBM Patient Samples and Protein Isolation From Tumor Tissues}

A total of 17 GBM tumor tissue samples were collected from Gazi University, Department of Neurosurgery, over the period April 2015-April 2016 with the approval of the Gazi University Clinical Research Ethics Committee. Tumor samples were fresh-frozen at $-80^{\circ} \mathrm{C}$. Two of the tumor tissues were excluded from the study as their pathology reports were found as GBM (-). 0.1 gram of tumor tissue sample was homogenized in RIPA lysis buffer. The lysate was centrifuged for 15 minutes at $14,000 \mathrm{rpm}$ and supernatant was collected to perform BCA protein quantification assay. Samples were stored at $-80{ }^{\circ} \mathrm{C}$ for further processing.

\section{Western Blotting}

T98G and U87-MG cells were washed with PBS and scraped into RIPA lysis buffer containing $1 \mathrm{mM}$ PMSF followed by sonication. Samples were centrifuged for 15 minutes at 13500 $\mathrm{rpm}$ at $4^{\circ} \mathrm{C}$ and supernatant was collected. Proteins were quantified by using BCA Assay Kit (Thermo Pierce, Rockford, IL, USA). Protein lysates $(20 \mu \mathrm{g})$ were heated for 5 minutes at $95^{\circ} \mathrm{C}$ in LDS non-reducing sample buffer (Pierce, Rockford, IL, USA) then loaded to $10 \%$ Tris-glycine gels, transferred to PVDF membrane (Pierce, Rockford, IL, USA). Membranes were blocked for 1 hour at room temperature and incubated overnight at $4^{\circ} \mathrm{C}$ with the primary antibodies for Casp3, Bcl2, Bad, Bax, GSK-3B, C-Myc and $\beta$-actin (Thermo Pierce, Rockford, IL, USA). Blots were visualized by Luminata Forte Western HRP Substrate (Merck Millipore, Darmtadt, Germany). Chemiluminescent signals of immunoblots were documented using Gel Logic 2200 Pro (Carestream Health; Rochester, NY, USA).

\section{Statistical Analysis}

Experiments were performed in triplicates. Metformin, dichloroacetate and memantine IC50 levels for T98G and U87-MG cell lines were calculated by using the Graph-Pad
Prism7. The results were expressed as the mean \pm standard deviation. $p<0.05$ was considered as statistically significant.

\section{RESULTS}

\section{Effects of Metformin, DCA, Metformin+DCA and Memantine on Cytotoxicity of T98G and U87-MG GBM Cells}

Metformin decreased the cellular viability of T98G and U87MG human GBM cancer cells in a dose-dependent manner as shown in Figure $1 \mathrm{~A}$, treatment with $45 \mathrm{mM}$ and $25 \mathrm{mM}$ metformin reduced cell viability for 48 hours $(p<0.01)$. We investigated the effect of DCA on T98G and U87-MG cells for 48 hours, $10-60 \mathrm{mM}$ concentration range of DCA was tested over cells. DCA reduced cell viability at $45 \mathrm{mM}$ concentration as shown in Figure 1B $(p<0.01)$. Different concentrations of metformin+DCA were also tested over GBM cells in order to decrease the IC50 doses. Metformin+DCA combination decreased cell viability to lower doses, IC50 dose for combination treatment was found as $20 \mathrm{mM}$ DCA and $20 \mathrm{mM}$ metformin for T98G and U87MG cells for 48 hours as shown in Figure $1 \mathrm{C}(\mathrm{p}<0.01)$. In addition, memantine affected cellular toxicity in a dose-dependent manner as shown in Figure 1D. 0.125-5 mM memantine concentration was tested over T98G and U87MG cells for 48 hours, and, IC50 value was determined as $0.5 \mathrm{mM}$ for T98G and for U87MG cells $(\mathrm{p}<0.01)$.

\section{Effects of Metformin, DCA, Metformin+DCA and Memantine on Casp3, Bcl2, Bax, c-Myc, GSK3B Protein Expression Levels}

T98G cells were treated with $45 \mathrm{mM}$ metformin, 45mM DCA, $20 \mathrm{mM}$ metformin in combination with $20 \mathrm{mM}$ of DCA and $0.5 \mathrm{mM}$ memantine for 48 hours. U87-MG cells were treated with $25 \mathrm{mM}$ metformin, $45 \mathrm{mM}$ DCA, $20 \mathrm{mM}$ of metformin in combination with $20 \mathrm{mM}$ of DCA and $0.5 \mathrm{mM}$ memantine for 48 hours. The expressions of apoptosis and cell-cycle progression related proteins i.e. Casp3, Bcl2, Bax, c-Myc and GSK3B, were evaluated by western blot. Metformin and metforminDCA combination decreased Casp-3 protein expression in T98G cells (Figure 2), whereas Casp-3 protein expression was increased in all treatments (metformin, DCA, metformin+DCA, memantine) in U87-MG cells (Figure 3). Bcl-2 protein expression was found to increase with DCA, metformin+DCA, and memantine treatment; whereas Bax protein expression was decreased in all treatments for T98G cells. c-Myc protein expression was decreased by the aforementioned treatments (metformin, DCA, metformin+DCA, memantine) in T98G cells. Memantine treatment inhibited GSK3B protein expression in T98G cells (Figure 2).

\section{Differential Protein Expression Profiles of GBM Positive Tumor Tissue}

GBM positive tumor tissue samples were characterized in terms of apoptosis as this might be an indicator of the disease progression. Fifteen $\mathrm{GBM}+$ tumor tissue samples were investigated for the Casp-3, Bcl-2, Bad, Bax protein expression profiles. Investigated apoptotic proteins were found to be differentially expressed at each patient (Figure 4). 


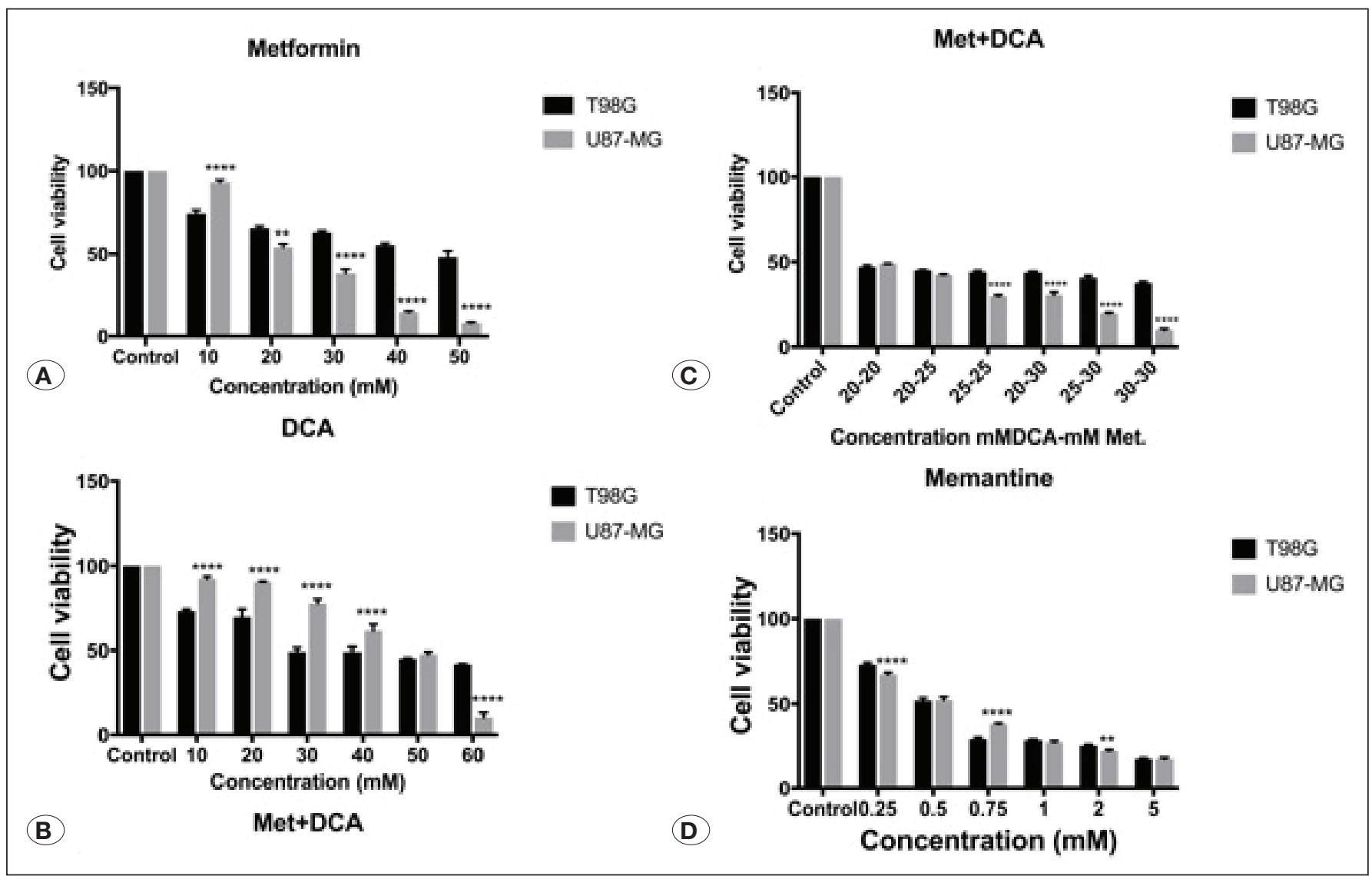

Figure 1: A) Metformin was tested over the range of 10-50 mM on T98G and U87-MG cells for 48 hours (h). IC50 value was determined as $45 \mathrm{mM}$ for T98G cells and $25 \mathrm{mM}$ for U87-MG cells $(\mathrm{p}<0.01)$. B) Dichloroacetate (DCA) was tested over the range of 10-60 mM on T98G and U87-MG cells for $48 \mathrm{~h}$. IC50 value was determined as $45 \mathrm{mM}$ for T98G and U87-MG cells $(\mathrm{p}<0.01)$. C) Metformin and DCA combination were tested over different ranges on T98G and U87-MG cells for $48 \mathrm{~h}$. IC50 value was determined as 20mM DCA and $20 \mathrm{mM}$ Metformin for T98G and U87-MG cells $(\mathrm{p}<0.01$ ). D) Memantine was tested over the range of 0.125-5 mM T98G and U87-MG cells for $48 \mathrm{~h}$. IC50 value was determined as $0.5 \mathrm{mM}$ for T98G and U87-MG cells $(p<0.01)$.

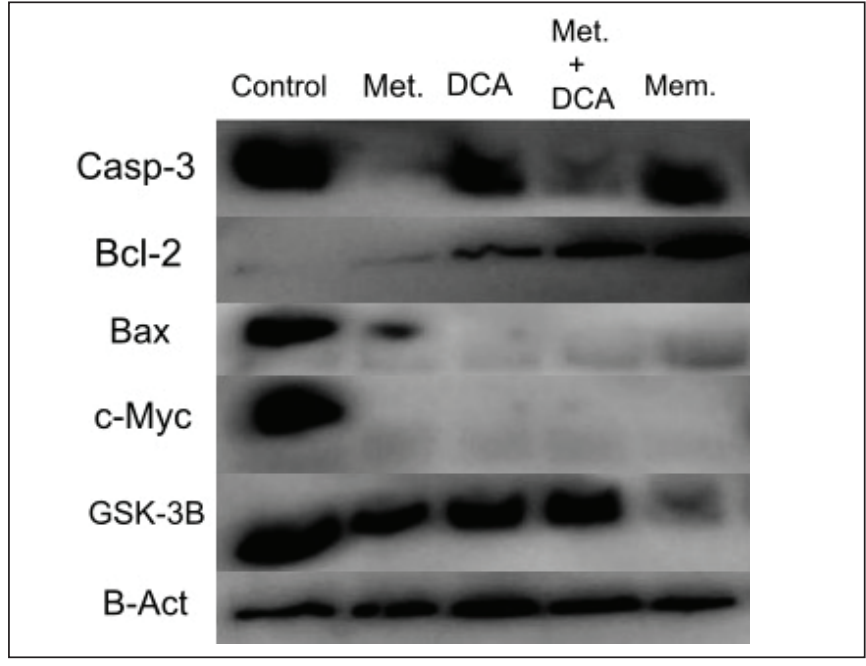

Figure 2: Effect of 48h treatment of T98G cell line with Metformin (45mM), DCA (45mM), Metformin+DCA combination (20mM $\mathrm{DCA}+20 \mathrm{mM}$ metformin) and Memantine $(0.5 \mathrm{mM})$ on the expression levels of: Casp3, Bcl-2, Bax, c-Myc and GSK-3B. B-Act protein expression was used as loading control.

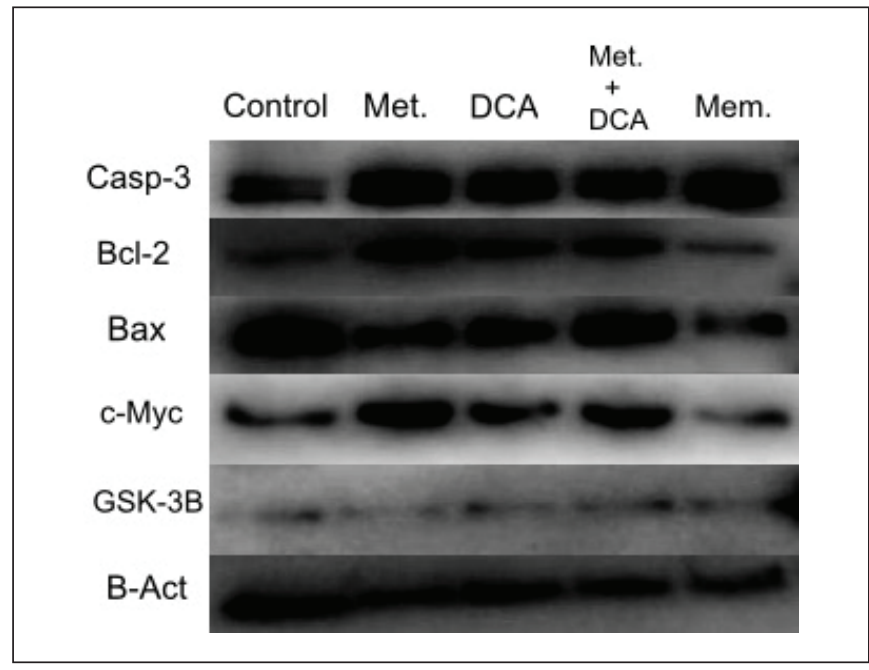

Figure 3: Effect of 48 hours treatment of U87-MG cell line with Metformin $(25 \mathrm{mM})$, DCA $(45 \mathrm{mM})$, Metformin+DCA combination (20mM DCA+20mM metformin) and Memantine $(0.5 \mathrm{mM})$ on the expression levels of: Casp3, Bcl-2, Bax, c-Myc and GSK-3B. $\mathrm{B}-$ Act protein expression was used as loading control. 


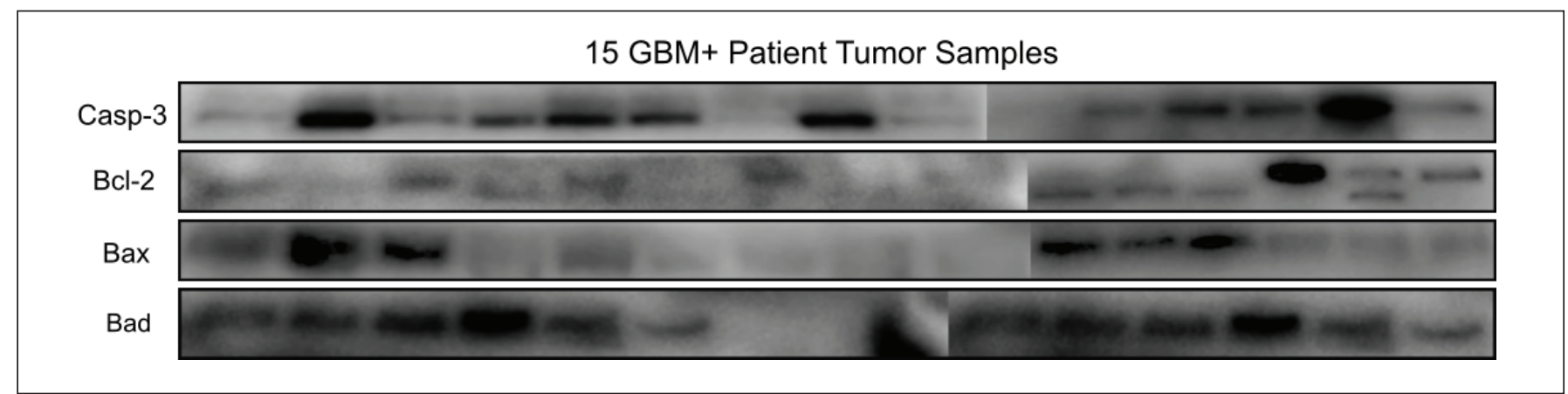

Figure 4: Differential protein expression profiles of 15 GBM+tumor tissue samples for apoptosis genes Casp-3, Bcl-2, Bad, Bax.

\section{DISCUSSION}

Anti-angiogenic drug bevacizumab approval in GBM showed improvement in the overall survival rate among patients; however, this finding remains controversial (6). There is a need for alternative treatment regimens for such an aggressive tumor GBM in this personalized medicine era.

Glucose and glutamine addiction of cancer cells is known as the hallmark of cancers (16). Aberrant glucose metabolism is defined as the drivers of GBM aggression and chemoresistance. Targeting tumor metabolism in cancer treatment has now widened interest beyond glucose metabolism to other molecules such as glutamine. It is, therefore, crucial to gain more insights into glutamine metabolism in cancer cells (2). It is thus the aim of the current study to target glucose and glutamine metabolism using metformin, DCA and memantine.

Diabetes drug metformin's mechanism of action over cancer cells is known as its selectivity in targeting cancer stem cells. This mechanism might be dependent on glutamine metabolism (8). DCA is a pyruvate dehydrogenase kinase inhibitor that reverses the Warburg effect (20). Sensitizing tumor cells to glycolysis inhibition might be achieved by dual targeting via metformin and DCA. In addition, Alzheimer's drug memantine has a much lower IC50 doses when compared to that of metformin. The relatively lower IC50 dose for memantine $(0.5 \mathrm{mM})$ might thus overcome the supra-physiological dose related concerns of metformin in clinical setting. Newly synthesized memantine derivatives were also found to have anti-tumor activities in U87-MG GBM cell line (3). Targeting NMDA receptor associated signalling pathways using memantine might enhance the treatment of glioma and GBM $(1,14)$. Enlightening memantine's anti-cancer mechanism over GBM cells, therefore, holds promise as a new repurposed drug.

Differential protein expression profiles of $15 \mathrm{GBM}+$ tumor tissues for apoptotic genes Casp-3, Bcl-2, Bad, Bax also confirms the heterogenic nature of the disease. Positive expression of Bax was associated significantly with the better survival rate in a large series of tumors (19). Bax protein expression profile, therefore, might be prognostic in GBM treatment response. Caspase- 3 activation is found to be a predictor of progression-free survival in GBM patients (13).
Molecular stratification of patients is indispensable to target patient groups that are most likely to get benefit from the selected treatment protocol.

In a recent study that transition into Phase II trial, researchers investigated the maximum tolerated doses of memantine, mefloquine, and metformin in combination with Temozolomide. Maraka et al. concluded that those drugs could be combined safely with Temozolomide in newly diagnosed GBM (10). Some side effects, however, were reported on the combined therapy regimens and the approach was scrutinized, raising the confusions on whether memantine or mefloquine caused the observed side effects (15). It remains crucial to understand the drug-to-drug and/or pharmacokinetic interactions when using drug combinations.

\section{CONCLUSION}

Our in vitro findings provide proof of concept that Alzheimer's drug memantine might be used in GBM treatment at lower doses compared to metformin. Brain blood barrier penetrating properties of memantine is also promising in GBM treatment. It is of further interest that memantine could provide an alternative neoadjuvant therapy especially for elderly cancer patients. This claim requires further investigation using randomized controlled trials.

\section{ACKNOWLEDGEMENTS}

This study has been supported by a scientific grant from the Scientific and Technological Research Council of Turkey, TUBITAK (Project No: SBAG- 214S578).

\section{REFERENCES}

1. Altinoz MA, Elmaci I: Targeting nitric oxide and NMDA receptor-associated pathways in treatment of high grade glial tumors. Hypotheses for nitro-memantine and nitrones. Nitric Oxide 79:68-83, 2018

2. Altman BJ, Stine ZE, Dang CV: From Krebs to clinic: Glutamine metabolism to cancer therapy. Nat Rev Cancer 16(10):619634, 2016

3. Cacciatore I, Fornasari E, Marinelli L, Eusepi P, Ciulla M, Ozdemir O, Tatar A, Turkez H, Di Stefano A: Memantinederived drugs as potential antitumor agents for the treatment of glioblastoma. Eur J Pharm Sci 109:402-411, 2017 
4. Ferla R, Haspinger E, Surmacz E: Metformin inhibits leptininduced growth and migration of glioblastoma cells. Oncology Letters 4(5):1077-1081, 2012

5. Inda MD, Bonavia R, Seoane J: Glioblastoma multiforme: A look inside its heterogeneous nature. Cancers 6(1):226-239, 2014

6. Johnson DR, Omuro AM, Ravelo A, Sommer N, Guerin A, Ionescu-Ittu R, Shi S, Macalalad A, Uhm JH: Overall survival in patients with glioblastoma before and after bevacizumab approval. Current Medical Research and Opinion 34(5):813820, 2018

7. Khosla D: Concurrent therapy to enhance radiotherapeutic outcomes in glioblastoma. Ann Transl Med 4(3):54, 2016

8. Kim JH, Lee KJ, Seo Y, Kwon JH, Yoon JP, Kang JY, Lee HJ, Park SJ, Hong SP, Cheon JH, Kim WH: Effects of metformin on colorectal cancer stem cells depend on alterations in glutamine metabolism. Scientific Reports 8(1):409, 2018

9. Liu Y, Xu X, Yin L, Zhang X, Li L, Lu H: Relationship between glioblastoma heterogeneity and survival time: An MR imaging texture analysis. Am J Neuroradiol 38(9):1695-1701, 2017

10. Maraka S, Groves MD, Mammoser AG, Melguizo-Gavilanes I, Conrad CA, Tremont-Lukats IW, Loghin ME, O'Brien BJ, Puduvalli VK, Sulman EP, Hess KR: Phase 1 lead-in to a phase 2 factorial study of temozolomide plus memantine, mefloquine, and metformin as postradiation adjuvant therapy for newly diagnosed glioblastoma. Cancer 125(3):424-433, 2019

11. Michelakis ED, Webster L, Mackey JR: Dichloroacetate (DCA) as a potential metabolic-targeting therapy for cancer. $\mathrm{Br} \mathrm{J}$ Cancer 99(7):989-994, 2008

12. Mrugala MM: Advances and challenges in the treatment of glioblastoma: A clinician's perspective. Discov Med 15(83):221-230, 2013

13. Murphy ÁC, Weyhenmeyer B, Schmid J, Kilbride SM, Rehm M, Huber HJ, Senft C, Weissenberger J, Seifert V, Dunst $M$, Mittelbronn M: Activation of executioner caspases is a predictor of progression-free survival in glioblastoma patients: A systems medicine approach. Cell Death Dis 4(5):e629, 2013

14. Müller-Längle $A$, Lutz $H$, Hehlgans $S$, Rödel $F$, Rau K, Laube $B$ : NMDA receptor-mediated signaling pathways enhance radiation resistance, survival and migration in glioblastoma cells-a potential target for adjuvant radiotherapy. Cancers (4):503, 2019

15. Nevin RL: Unexpectedly low rates of neuropsychiatric adverse effects associated with mefloquine repurposed for the treatment of glioblastoma. Cancer 125(8):1384-1385, 2019

16. Panchanathan RS, Sittur MG, Aoun RJ, Pines AR, Swanson $\mathrm{KR}$, Bendok BR: War on glioblastoma multiforme: 2-pronged siege on glutamine. World Neurosurgery 91:254-256, 2016
17. Parsons DW, Jones S, Zhang X, Lin JC, Leary RJ, Angenendt P, Mankoo P, Carter H, Siu IM, Gallia GL, Olivi A, McLendon R, Rasheed BA, Keir S, Nikolskaya T, Nikolsky Y, Busam DA, Tekleab H, Diaz Jr LA, Hartigan J, Smith DR, Strausberg RL, Nagahashi Marie SK, Oba Shinjo SM, Yan H, Riggins GJ, Bigner DD, Karchin R, Papadopoulos N, Parmigiani G, Vogelstein B, Velculescu VE, Kinzler KW: An integrated genomic analysis of human glioblastoma multiforme. Science 321(5897):1807-1812, 2008

18. Rojas LBA, Gomes MB: Metformin: An old but still the best treatment for type 2 diabetes. Diabetol Metab Syndr 5(1):6, 2013

19. Ruano Y, Mollejo M, Camacho FI, de Lope AR, Fiaño C, Ribalta T, Martinez P, Hernández Moneo JL, Meléndez B: Identification of survival related genes of the phosphatidylinositol 3' kinase signaling pathway in glioblastoma multiforme. Cancer 112(7):1575-1584, 2008

20. Shen H, Decollogne S, Dilda PJ, Hau E, Chung SA, Luk PP, Hogg PJ, McDonald KL: Dual-targeting of aberrant glucose metabolism in glioblastoma. J Exp Clin Cancer Res 34(1):14, 2015

21. Soeda A, Hara A, Kunisada T, Yoshimura SI, Iwama T, Park DM: The evidence of glioblastoma heterogeneity. Scientific Reports 5:7979, 2015

22. Sottoriva A, Spiteri I, Piccirillo SG, Touloumis A, Collins VP, Marioni JC, Curtis C, Watts C, Tavaré S: Intratumor heterogeneity in human glioblastoma reflects cancer evolutionary dynamics. Proc Natl Acad Sci U S A 110(10):40094014, 2013

23. Stupp R, Mason WP, Van Den Bent MJ, Weller M, Fisher B, Taphoorn MJ, Belanger K, Brandes AA, Marosi C, Bogdahn U, Curschmann J, Janzer RC, Ludwin SK, Gorlia T, Allgeier A, Lacombe D, Cairncross JG, Eisenhauer E, Mirimanoff RO, European Organisation for Research and Treatment of Cancer Brain Tumor and Radiotherapy Groups; National Cancer Institute of Canada Clinical Trials Group: Radiotherapy plus concomitant and adjuvant temozolomide for glioblastoma. N Engl J Med 352(10):987-996, 2005

24. Quinn BJ, Kitagawa H, Memmott RM, Gills JJ, Dennis PA: Repositioning metformin for cancer prevention and treatment. Trends in Endocrinology \& Metabolism 24(9):469-480, 2013

25. Whitburn J, Edwards CM, Sooriakumaran P: Metformin and prostate cancer: A new role for an old drug. Current Urology Reports 18(6):46, 2017

26. Yang SH, Li S, Lu G, Xue H, Kim DH, Zhu JJ, Liu Y: Metformin treatment reduces temozolomide resistance of glioblastoma cells. Oncotarget 7(48):78787-78803, 2016

27. Zhang X, Zhang W, Cao WD, Cheng G, Zhang YQ: Glioblastoma multiforme: Molecular characterization and current treatment strategy. Exp Ther Med 3(1):9-14, 2012 